\title{
Effects of TV advertising on children and parental influence on children's TV viewing
}

\begin{abstract}
The objective of this study is to investigate the effects of children advertising on children and parental influences on the childrenôs attitude and understanding levels toward children advertisements on television. The respondents for this study were both parents and children. Among others, the study revealed the childrenôs inability to distinguish commercials from TV programmes and to differentiate fantasy from reality. These inabilities, however, differed with childrenôs age levels. Further, the results indicate that parents have an influence over the childrenôs understanding levels with respect to children advertisements in television.
\end{abstract}

Keyword: Children advertisements; Children; Television; Parental influences 